\title{
Visible Light Communications towards 5G
}

\author{
Stanislav ZVANOVEC ${ }^{1}$, Petr CHVOJKA ${ }^{1}$, Paul Anthony HAIGH ${ }^{2}$, Zabih GHASSEMLOOY ${ }^{3}$ \\ ${ }^{1}$ Dept. of Electromagnetic Field, Czech Technical University in Prague, Technicka 2, 16627 Prague, Czech Republic \\ ${ }^{2}$ Faculty of Engineering, University of Bristol, Bristol, BS8 1TR, UK \\ ${ }^{3}$ Optical Communications Research Group, Faculty of Engineering and Environment, Northumbria University, \\ Newcastle-upon-Tyne NE1 8ST, UK
}

xzvanove@fel.cvut.cz, petr.chvojka@fel.cvut.cz,paul.anthony.haigh@bristol.ac.uk, z.ghassemlooy@northumbria.ac.uk

\begin{abstract}
G$ networks have to offer extremely high capacity for novel streaming applications. One of the most promising approaches is to embed large numbers of cooperating small cells into the macro-cell coverage area. Alternatively, optical wireless based technologies can be adopted as an alternative physical layer offering higher data rates. Visible light communications (VLC) is an emerging technology for future high capacity communication links (it has been accepted to 5GPP) in the visible range of the electromagnetic spectrum $(\sim 370-780 \mathrm{~nm})$ utilizing light-emitting diodes (LEDs) simultaneously provide data transmission and room illumination. A major challenge in VLC is the LED modulation bandwidths, which are limited to a few MHz. However, myriad gigabit speed transmission links have already been demonstrated. Non line-of-sight (NLOS) optical wireless is resistant to blocking by people and obstacles and is capable of adapting its' throughput according to the current channel state information. Concurrently, organic polymer LEDs (PLEDs) have become the focus of enormous attention for solid-state lighting applications due to their advantages over conventional white LEDs such as ultra-low costs, low heating temperature, mechanical flexibility and large photoactive areas when produced with wet processing methods. This paper discusses development of such VLC links with a view to implementing ubiquitous broadcasting networks featuring advanced modulation formats such as orthogonal frequency division multiplexing (OFDM) or carrier-less amplitude and phase modulation (CAP) in conjunction with equalization techniques. Finally, this paper will also summarize the results of the European project ICT COST IC1101 OPTICWISE (Optical Wireless Communications - An Emerging Technology) dealing VLC and OLEDs towards $5 G$ networks.
\end{abstract}

\section{Keywords}

5G networks, light emitting diodes, visible light communications

\section{Introduction}

In recent years, the worldwide growth in mobile data traffic has led to the development of new technologies for future high capacity communication systems. Every year the number of wireless devices such smartphones, laptops and tablets increases, thus multimedia content becomes the main part of the overall mobile data transferred. This fact results in an increasing throughput requirement from the next generation of communication networks (5G), which are expected to be deployed beyond 2020. Network designers face several critical challenges, all of which need to be addressed, such as optimal spectra allocation, high capacity broadband links, power consumption, quality of services (QoS) and mobility. For instance, approximately one exabyte (EB) of data was transferred across the entire global internet in 2000 (0.083 EB/month) [1]. In contrast, $\sim 30$ times more data was carried by the mobile networks per month in 2014 , which corresponds to $\sim 2.5 \mathrm{~EB} /$ month (refer to Fig. 1). Moreover, the latest projections from Cisco predict that the overall mobile data traffic will reach approximately $24 \mathrm{~EB} /$ month by 2019 , which is approximately one order of magnitude larger than 2014 (Fig. 1). This corresponds to a compound annual growth rate (CAGR) of 57\% for the 2014-2019 period. Following the projection Fig. 1 also shows the fit for this data, which estimates that $>30 \mathrm{~EB} /$ month will be transmitted beyond 2020. Most of this mobile data traffic (up to $69 \%$ ) is expected to consist of video and media by the end of 2018 [1].

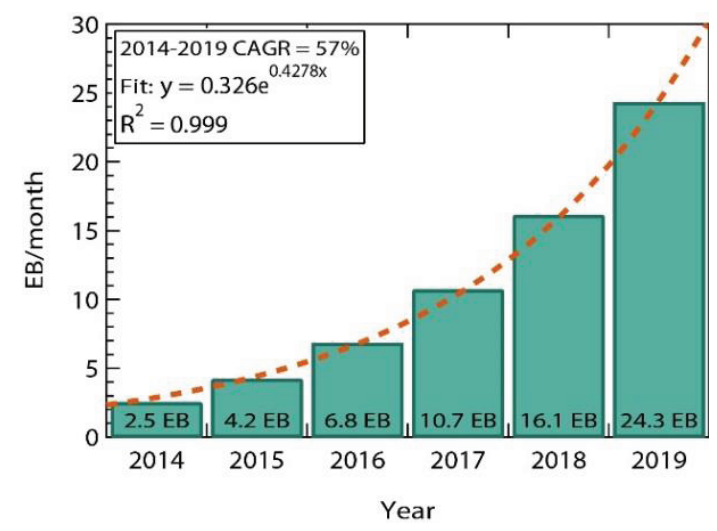

Fig. 1. A prediction of the mobile data traffic per month.

$5 \mathrm{G}$ networks are expected to meet all the mentioned requirements [2], [3]. The network architecture is expected to be changed dramatically and the limited frequency bands must be used more efficiently. Future systems will be based on heterogeneous networks (HetNets) and advanced radio 
access technologies (RATs). HetNets include several small cells featuring low transmission power and small coverage area, thus enabling high cell density. Such a system configuration allows spectral reuse, hence improving the capacity of the wireless channel [2], [3], [4]. The cellular architecture should be designed to separate indoor and outdoor scenarios and support massive multiple-input multipleoutput (MIMO) technologies with distributed antenna systems [2], [3].

As the number of communication devices increases and the demand for connections grows, power efficiency becomes one of the most important issues for $5 \mathrm{G}$ networks. Around $2 \%$ of all carbon-dioxide emissions worldwide are produced by communication technologies; this will increase significantly with the aforementioned increasing mobile data traffic demand [5]. Moreover, $\sim 57 \%$ of overall wireless network energy consumption is dissipated in radio access nodes [6]. Thus, 'green' and energy efficient systems should reduce the $\mathrm{CO}_{2}$ emissions and decrease the operating costs.

Indoor communication systems can offer a solution to all the above issues, such as mm-wave systems (3 to $300 \mathrm{GHz})$ or optical wireless communications such as VLC, which is carried at $400-490 \mathrm{THz}$. 5G-VLC offers a number of small cells, also referred to as attocells in the literature, in the indoor environment, thus enabling many advantages such as high capacity data transmission, excellent mobility and energy efficient management. Recent experiments demonstrated up to $1.6 \mathrm{Tbit} / \mathrm{s}$ for optical wireless backhaul links at $1550 \mathrm{~nm}$ [7] and up to $3.4 \mathrm{Gbit} / \mathrm{s}$ [8] in VLC based access networks. Moreover, two functionalities are provided with VLC, i.e. the combining of data transmission with illumination of the room using lightemitting diodes (LEDs), which is not available with other network technologies. This paper provides a wide overview of the VLC technology and summarizes its development and the state-of-the-art. The rest of the paper is organized as follows: Section 2 describes the fundamental VLC principles with emphasis on inorganic and organic LEDs, Section 3 is focused on the modulation formats and finally in Section 4, perspective VLC applications are discussed.

\section{Visible Light Communications Technology}

License-free spectrum, practically unlimited channel bandwidth, high capacity links and energy efficiency are the main features of light fidelity (Li-Fi) networks. Li-Fi is a subset of the VLC domain, which refers to broadcasting access networks with multiple users. The transmitter consists of LEDs either singularly or in an array that are intensity modulated at a rate above which it is not perceivable by the human eye. Since full room illumination is required, the visible range of the electromagnetic spectrum $(\sim 370$ to $780 \mathrm{~nm}$ ) is utilized in VLC. Moreover, VLC has been proposed for future $5 \mathrm{G}$ networks standards.
There are two types of LEDs used to produce white light: (i) inorganic metal alloy semiconductor LEDs (usually a blue emitting gallium nitride $(\mathrm{GaN})$ interface with a cerium doped yttrium aluminum garnet (Ce:YAG) color converting phosphor) and (ii) organic LEDs (OLEDs) made from either small molecules or polymers, using epitaxial or wet processing methods, respectively [9], [10]. Inorganic LEDs are commonly used in VLC, while generic OLEDs are attracting significant attention for future VLC networks. When dissolved into solvents and processed with wet methods (i.e. inkjet printing, spray coating) polymer based OLEDs offer several significant advantages over inorganic devices, namely; large, arbitrarily shaped photoactive areas limited only by the size of the printing apparatus, mechanical flexibility, low temperature and ultralow costs.

\subsection{Inorganic LEDs}

The most common type of inorganic LEDs producing white light are Ce:YAG converted GaN diodes, as mentioned, which are known as white phosphor LEDs (WPLEDs). Alternatively, white light can be produced using a single LED package with on-board red, green and blue (RGB) chips. Considering WPLEDs, the main impediment in achieving high data rates is the modulation bandwidth. GaN diodes can offer modulation bandwidths up to several hundred $\mathrm{MHz}$ [11], however the Ce:YAG phosphor layer has a slow transient response, reducing the bandwidth down to the low $\mathrm{MHz}$ region, which common values around $4-5 \mathrm{MHz}$ [12]. Thus, increasing the transmission capacity is the key challenge undertaken by researchers. However, the concept of micro-LEDs was introduced in [13], where the photoactive area of the device is reduced significantly to the $\mu \mathrm{m}$ scale, thus relieving the plate capacitance of the device and increasing the bandwidth. Depending on the photoactive area diameter, bandwidths exceeding $400 \mathrm{MHz}$ were demonstrated. Such a device can provide a $3.22 \mathrm{~Gb} / \mathrm{s}$ throughput when using an adaptive bitand power-loading technique [14]. On the other hand, reducing the photoactive area means a reduction in optical power, which in turn severely limits the transmission distance. In [13], the optical power ranged from $\sim 0.5 \mathrm{~mW}$ to $\sim 5 \mathrm{~mW}$, which is significantly smaller than standard GaN LEDs.

VLC links at $\mathrm{Gb} / \mathrm{s}$ data rates have already been demonstrated, despite the very limited LED modulation bandwidths. A popular method to increase the capacity of VLC links is to use spectrally efficiency modulation formats such as discrete multi-tone (DMT) [8], [15]. A $3.4 \mathrm{~Gb} / \mathrm{s}$ transmission speed was achieved in [8] using a single RGB LED and DMT modulation at a distance $<30 \mathrm{~cm}$. Wavelength division multiplexing (WDM) was utilized to transmit independent streams of information on each wavelength. Nevertheless, DMT requires complex signal processing and a feedback channel for bit- and powerloading. A similar approach was adopted in [15] resulting in a transmission speed of $1 \mathrm{~Gb} / \mathrm{s}$ at a $10 \mathrm{~cm}$ distance. 
Another possibility for increasing the channel capacity is the implementation of an equalizer [12]. On-off keying $(\mathrm{OOK})$ is the most common modulation format due to simplicity of implementation and compatibility with equalizers. In [12] several equalizers were tested on a commercially available digital signal processing (DSP) board. The LED had low modulation bandwidth $(4.5 \mathrm{MHz})$ and transmission speeds up to $170 \mathrm{Mb} / \mathrm{s}$ were recorded using a highly complex artificial neural network (ANN) based equalizer. Real time data processing on field programmable gate arrays (FPGAs) is the next step towards building a fully real time system, as currently most reports in the literature feature offline processing.

\subsection{Organic LEDs}

There are two types of OLEDs, the first produced using small molecules (SMOLEDs) and the second with polymers (PLEDs). Due to the previously mentioned advantages, organic materials have been focus of the research to be implemented in communication systems. According to [16], the global organic electronic market will approach $\$ 80$ billion by 2020 , thus resulting in (CAGR) of $29.5 \%$ between $2014-2020$.

A possible and generic PLED structure is depicted in Fig. 2. It consists of thin films (total thickness 1-200 nm) of organic emissive and charge transport layers. Polymers such as:

(i) red: poly[2-methoxy-5-(3',7'-dimethyloctyloxy)-1,4phenylenevinylene] (MDMO-PPV)

(ii) green: poly[(9,9-di-n-octylfluorenyl-2,7-diyl)-alt(benzo[2,1,3] thiadiazol-4,8-diyl)] (F8BT) and

(iii) blue: poly(9,9-dioctylfluorene), (poly(9,9-dioctylfluorene-alt-N-(4-butylphenyl)diphenylamine) and poly(9,90-dioctylfluorene-alt-bis-N,N0-(4-butylphenyl)-bis-N,N0-phenyl-1,4-phenylenediamine) (F8:TFB:PFB)

are evaluated as the emissive layer in [17] while a poly $(3,4-$ ethylenedioxythiophene) (PEDOT) doped with poly(styrenesulfonic acid) (PSS) interlayer is used consistently for the charge transport layer in order to minimize the energy gap between the electrode and emissive layer. In Fig. 2 the PLED is a bottom emitter and hence the anode must be transparent (generally indium tin oxide (ITO) is used). When positive and negative charges recombine, the charges combine for a fraction of a second as Frenkel excitons before the energy is emitted as photons. The material can be placed on various substrates including plastic, enabling flexibility.

However, the most limiting factor for OLEDs is very low modulation bandwidth, which is much lower than the bandwidth of conventional inorganic diodes. The reason for this is because the charge transport characteristics of organic materials are approximately three orders of magnitude lower than those of amorphous silicon (a-Si). OLEDs act as a low pass filter with a certain cut-off frequency. The $-3 \mathrm{~dB}$ frequency is given by:

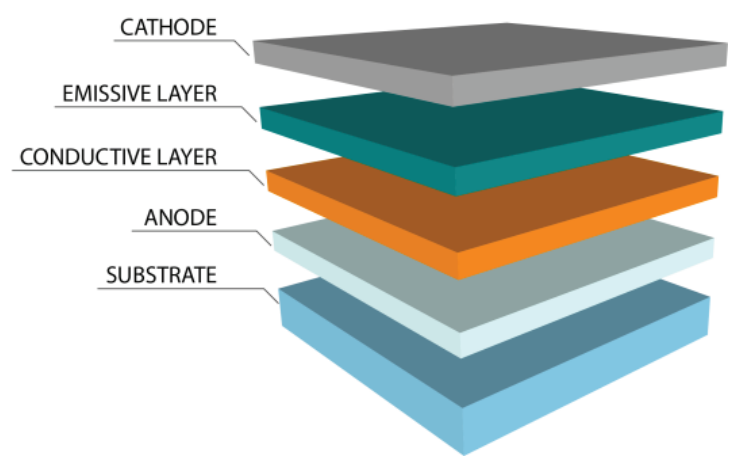

Fig. 2. The structure of OLED.

$$
f_{\mathrm{c}}=\frac{1}{2 \pi R C}
$$

where $R$ is the effective resistance and $C$ is the plate capacitance, given as:

$$
C=A \varepsilon_{0} \varepsilon_{r} / d
$$

where $A$ is the photoactive area and $d$ is thickness of OLED, $\varepsilon_{0}$ and $\varepsilon_{r}$ are the relative permittivity of free space and the emissive layer, respectively. As $d$ is generally very small (1-200 nm), this tends to a large $C$, hence a very high capacitance and low bandwidth, which is typically in the order of several hundred $\mathrm{kHz}$ [18]. On the other hand, OLEDs with bandwidths up to $\sim 60 \mathrm{MHz}$ were reported in [19], which was achieved by reducing the photoactive area to $0.018 \mathrm{~mm}^{2}$. Using commercial and custom OLEDs, promising experimental results have been reported in the literature. A SMOLED with a bandwidth $93 \mathrm{kHz}$ is modulated by DMT signal to demonstrate to data rate up to $1.4 \mathrm{Mb} / \mathrm{s}$ in [20]. A two-fold improvement of this transmission speed was published in [21] using the same SMOLED as in [20]; a $2.7 \mathrm{Mb} / \mathrm{s}$ link is shown using a multi-layer perception (MLP) ANN equalizer offline in MATLAB.

A breakthrough in organic VLC was made in [22], where PLEDs were used to demonstrate transmission speeds in excess of that required for Ethernet connectivity. The data rate of $20 \mathrm{Mb} / \mathrm{s}$ was reported in [22], [23] using OOK format and an MLP equalizer. More recently in [17], an aggregated transmission speed of $55 \mathrm{Mb} / \mathrm{s}$ was experimentally demonstrated and was achieved using an RGB PLED and WDM, which is a promising improvement for future research activities.

\subsection{Other Organic Components}

Organic photodetectors (OPD) are also a promising technology and can substitute silicon photodiodes in specific applications. OPDs used in the authors' previous work are based on the bulk heterojunction principle [24]; an interpenetrated and disordered blend of an electron donor and electron acceptor and were fabricated using spray coating [25]. The material costs for the poly(3hexylthiophene): [6,6]-phenyl C61-butyric acid methylester (P3HT:PCBM) blend are around $€ 0.20 / \mathrm{cm}^{2}$. Furthermore, OPDs can offer superior responsivity in comparison to $\mathrm{Si}$ photodetectors in the visible spectrum as shown in Fig. 3. 


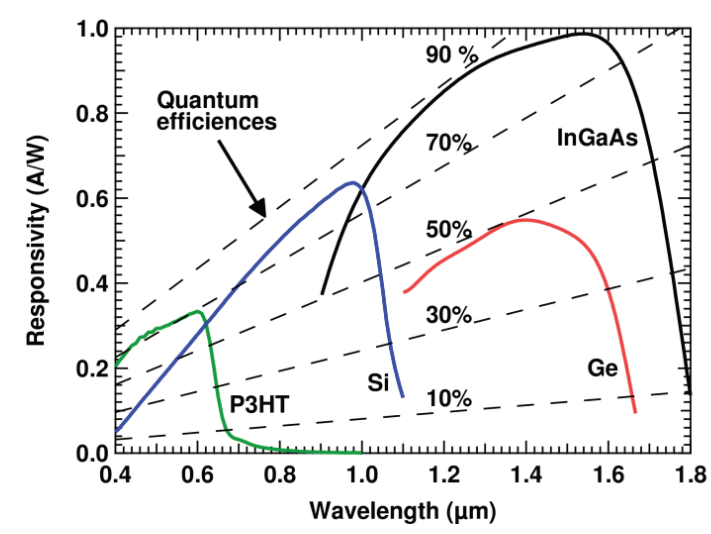

Fig. 3. Photodetector material responsivities.

The OPD with raw $3 \mathrm{~dB}$ bandwidth of $30 \mathrm{kHz}$ is tested in [26] with the resulting data rate of $750 \mathrm{~kb} / \mathrm{s}$, which is $\sim 20$ times increment representing huge potential of such devices. An OPD with $\sim 160 \mathrm{kHz}$ modulation bandwidth is utilized in [27]. Fourth-order pulse position modulation (4-PPM) and an ANN equalizer were used to achieve a transmission speed of $3.75 \mathrm{Mb} / \mathrm{s}$. Fully organic VLC link was introduced in [28], where the low bandwidth components (up to $135 \mathrm{kHz}$ ) with OOK modulation and ANN based filtering were used to achieve data rate exceeding $1 \mathrm{Mb} / \mathrm{s}$.

\section{Modulation Formats}

Besides equalization techniques, spectrally efficient modulation formats such as orthogonal frequency division multiplexing (OFDM) are a popular way to increase the VLC link capacity. For instance, Gb/s transmissions were reported in [8] and [29] by implementing DMT. Power efficient schemes such as low peak-to-average power ratio (PAPR) single carrier frequency-domain equalization (SCFDE) was proposed in [30]. Here the IFFT block was moved to the receiver side to avoid the generation of complicated waveforms and consequently reduced PAPR. Further spectral efficiency improvements have been achieved by adopting novel OFDM SC-FDE signal formats - polar OFDM and polar SC-FDE in [31].

Recently, carrier-less amplitude and phase modulation (CAP) has appeared as a candidate for optical systems, which outperforms OFDM channel using the same experimental setup [32]. CAP systems have several advantages over OFDM including no Fourier transform as in OFDM or local oscillator, which is utilized in a single carrier modulations such as quadrature amplitude modulation (QAM). The carrier frequencies in CAP are generated by either analogue or digital finite impulse response filters (FIR).

Unlike OFDM, a flat frequency response is required for CAP meaning the low bandwidths available are the major problem once more, due to the $20 \mathrm{~dB}$ /decade attenuation for frequencies outside the bandwidth. A possible solution for this was introduced in [33], where the available

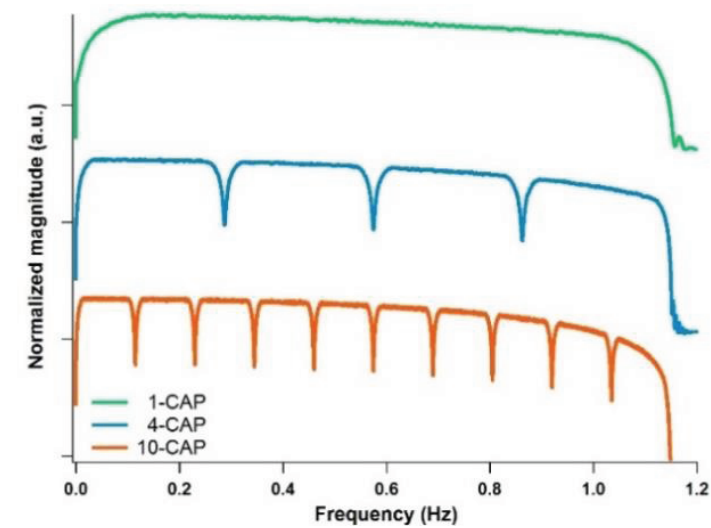

Fig. 4. The concept of m-CAP modulation, where the available system bandwidth is split into 1,4 and 10 subbands.

bandwidth is divided into a multiband ( $m$-CAP) format for an optical fiber channel. The transmission bandwidth was split into 6 sub-bands (subcarriers) and the performance was compared with the traditional CAP (1-CAP) system. The fiber system transmission speed was $102.4 \mathrm{~Gb} / \mathrm{s}$ and $100 \mathrm{~Gb} / \mathrm{s}$ for $m$-CAP and 1-CAP, respectively, which is not a significant gain, however a gain in transmission speed was not the focus of the article. The $m$-CAP system noted a significant improvement in dispersion tolerance. Nevertheless, for 1-CAP transmission, two FIR filters are required for signal generation. As $m$ increases, the number of FIR filters grows by $2 m$. Thus, one must consider an increment in the system complexity resulting from a multiband approach. On the other hand, such a concept allows optimization of the modulation format used in each subband according to measured signal-to-noise ratio (SNR), i.e. bit- and power-loading in OFDM. The principle of $m$-CAP is illustrated in Fig. 4. The available system bandwidth is split into $m$ sub-bands. The more sub-bands are utilized, the less bandwidth is occupied by a single subcarrier, thus resulting in a reduced attenuation caused by the LED low-pass frequency response.

A detailed description of the $m$-CAP modulation format and signal generation can be found in [34], [35]. The first VLC experiment utilizing $m$-CAP was reported in [35], where a data rate of $31.5 \mathrm{Mb} / \mathrm{s}$ was demonstrated using 10-CAP; resulting in a spectral efficiency of $4.85 \mathrm{~b} / \mathrm{s} / \mathrm{Hz}$, which offers huge potential for a future research.

\section{Applications}

As the technology has evolved over the last decade and with rapid increase of mobile data requirements, there are several challenging areas for specific deployment of VLC systems. Alongside classic indoor communication schemes (i.e., broadcasting networks), VLC can also be utilized for localization or car-to-car and car-to-infrastructure communications. The following sections highlight the main approaches and principles. 


\subsection{Indoor Communications}

Alongside illumination and data communications, VLC systems have been proposed for indoor positioning with a very high accuracy (a few $\mathrm{cm}$ ). The IEEE 802.15.7 task group [36] has been forming the new standard for VLC, orienting their efforts towards the PHY and MAC standards since 2009. The main focus from the first releases had been given on slow VLC for indoor positioning by means of optical camera communication. More recently high bit rate VLC transmission systems are under standardization, especially based on results produced by the EU COST IC1101 project OPTICWISE consortium.

For indoor applications with a static environment, VLC can offer high QoS even when the movement of people and shadowing by obstacles perturb the beam (so called non-line of sight (NLOS)). This has been proved by several theoretical and experimental investigations [37], [38]. Typically, such NLOS systems use diffuse reflections, where the transmitter illuminates the ceiling, and/or wide field-ofview or receiving apertures instead of direct links. Data rates up to $400 \mathrm{Mbit} / \mathrm{s}$ have been reported for a NLOS link in [39]. The first mobile VLC system was reported for typical indoor distances between $2 \mathrm{~m}$ and $20 \mathrm{~m}$ with data rates decreasing with distance from approx. $500 \mathrm{Mbit} / \mathrm{s}$ to $100 \mathrm{Mbit} / \mathrm{s}$ in [40].

The typical model of diffuse reflection was described in [41]. The power efficiency for the diffuse signal can be derived as [41]:

$$
\mu_{\text {diff }}=\frac{P_{\text {diff }}}{P_{\mathrm{T}}}=\frac{A_{\mathrm{R}} \sin ^{2}(F O V / 2)}{A_{\text {room }}} \frac{\langle\rho\rangle}{1-\langle\rho\rangle}
$$

where $\langle\rho\rangle$ is mean reflectivity, $F O V$ stands for field of view of detector and $A_{\mathrm{R}}$ and $A_{\text {room }}$ are areas of detector and room, respectively. The decay time then can be given as [41]:

$$
\tau=-\frac{\langle t\rangle}{\ln \langle\rho\rangle} .
$$

The average time $\langle t\rangle$ between two diffuse reflections for a rectangular room with dimensions $l \times w \times h$ (length $\times$ width $\times$ height) is expressed by [41]:

$$
\langle t\rangle=\frac{2 l w h}{c(l w+l h+w h)} .
$$

The DC gain of the reflected path can afterwards be determined as [10]:

$$
H_{\mathrm{ref}}(O)= \begin{cases}\frac{(m+1)}{2\left(\pi d_{1} d_{2}\right)^{2}} \rho A_{\mathrm{det}} d A_{\mathrm{w}} \cos ^{m}\left(\theta_{r}\right) \cos (\alpha) \\ \cdot \cos (\beta) T_{\mathrm{S}}(\vartheta) g(\vartheta) \cos (\vartheta) & \text { for } 0 \leq \vartheta \leq \vartheta_{\mathrm{FOV}} \\ 0 & \text { for } \vartheta>\vartheta_{\mathrm{FOV}}\end{cases}
$$

where $d_{1}$ is the distance between the transmitter and the reflective point, $d_{2}$ is the distance between the reflective point and the receiver, $\rho$ is the reflectance coefficient, $d A_{\mathrm{w}}$

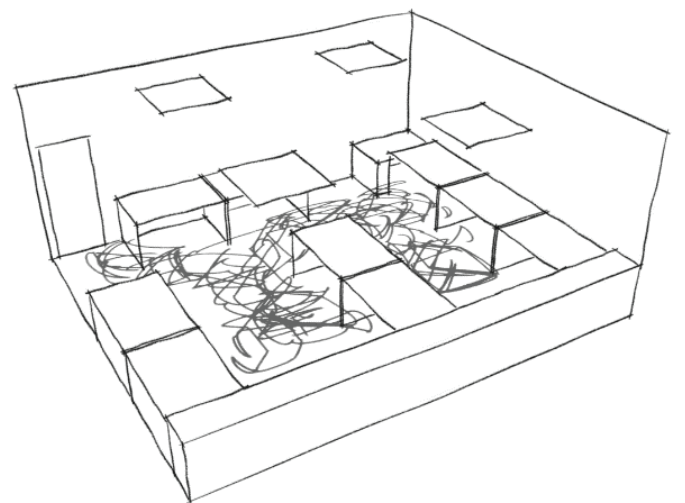

Fig. 5. The simulation of people's movement within an office using VLC with 4-LED.

is a small reflective area on the wall, $\alpha$ is the angle of incidence from the transmitter and $\beta$ is the angle of irradiance from a reflected point.

Fig. 5 illustrates people's movement within a typical office environment utilizing VLC by employing 4 LEDs mounted on the ceiling.

In such a case sometimes the direct paths from transmitter to receiver are blocked or temporally shadowed by a human. Several studies derived the percentage of shadowing. For instance [42] reported shadowing with a probability of $<2 \%$ for a multiple-input multiple-output (MIMO) system covering a typical office. Similar results were derived in [43] where time division multiple access was investigated. Higher order reflections induce significant influence on the temporal dispersion according to [37], [38]. The reflection component always appears respective to
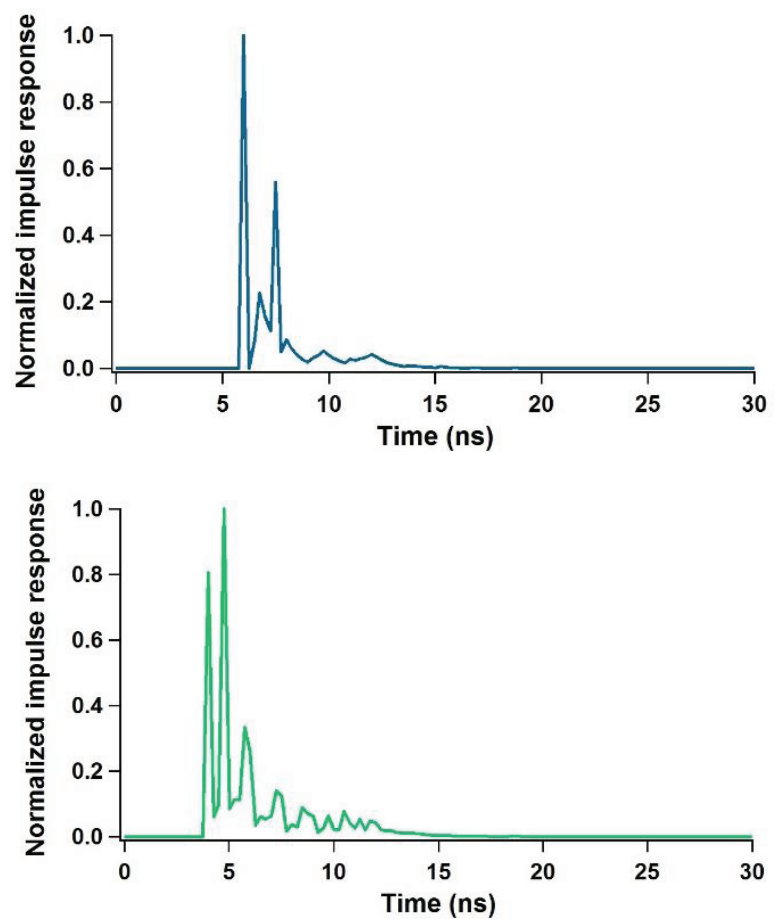

Fig. 6. Examples of the normalized channel impulse response for LOS/NLOS scenario considering blocking signal path by people in an office with: a) 4 LEDs, b) 18 LEDs. 
LOS incident paths [38]. This influence can be easily observed in the transmission bandwidth. Two examples of a normalized channel response for the scenario shown in Fig. 5 are illustrated in Fig. 6.

The measured probability density function of the normalized received optical power considering people's movement as well as the analysis of the RMS delay spread for different indoor scenarios and people densities in rooms was carried out in [44]. Based on the measurement campaign the normalized received power showed a Rayleigh distribution with the scale parameter varying from 0.98 to 1.79 for an empty to a crowded room. The RMS delay spread statistics have been derived for three different indoor scenarios. For the case of furnished office environment (people density $>0.16$ people $/ \mathrm{m}^{2}$ ), the cumulative distribution function (CDF) of the received power differs in the worst case by up to $7 \%$ contrary to an RMS delay of $2 \%$ that was experienced under the same people density in the corridor [44].

\subsection{Positioning and Localization}

Several positioning systems have been tested over the last few years. In [45] a digital camera was used as a receiver to capture a sequence of images of the LED positioning beacon transmitter. By using image-processing algorithms, the system was able to decode the location information encoded in the visual patterns transmitted by LEDs. The system demonstrated that improved performance can be attained even at low values of SNR. A system for localization of vehicles using the global positioning system (GPS) together with a light beacon device mounted on the vehicle to receive information from transmitter positioned at the road intersections is developed by Honda motors Co., Ltd. in 2010 [46].

Another challenge represents the utilization of the localization within the indoor scenario, where standard GPS signals cannot be received (see illustrative deployment in Fig. 7). In recent years, we have seen research and development in optical based indoor positioning schemes (IPS) offers multitude of advantageous including smaller transceiver size, immunity to electromagnetic interference, and inherent security [47]. VLC based IPS offers the advantage of LED and VLC technologies such as ubiquitous coverage, static channel, multiple lighting elements etc. [48]. Using VLC with synchronization between the transmitter

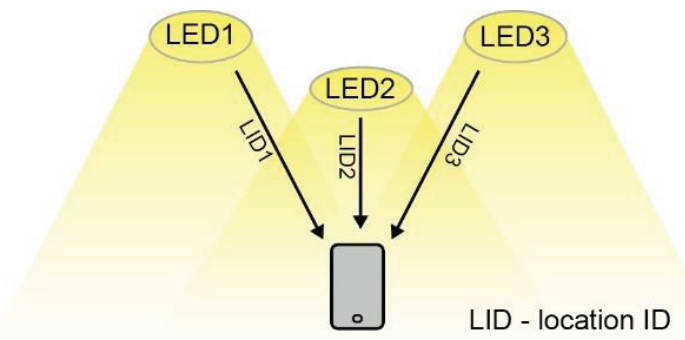

Fig. 7. Concept of VLC positioning system (multi-access mechanism among single terminal and multiple lights + position estimation). and receiver, the bounds on position estimation accuracy are typically in the order of millimeters or centimeters depending on the geometry of the room, the frequency and power of the transmitted signal and the properties of the LED and the photoreceiver [49]. A VLC-based IPS employing 3-LED, the dual-tone multi-frequency technique and a dedicated algorithm was reported in [48]. Unlike the time-division multiplexing based VLC-IPS, this scheme does not require synchronization between the transmitter and receiver, thus makes it simple, robust and cost effective. VLC-IPS is highly accurate offering an average positioning error of about $1.6 \mathrm{~cm}$, which is much less than many existing IPS.

Typically several transmitters serve as beacons and the RMS delay spread can be used to quantify the amount of multipath distortion that can occur at a particular point within a room [50]. Parameter $D_{\text {rms_Max }}$ corresponds to the largest multipath distortion, which limits the maximum transmission data rate $R_{\max }$ of the system. $R_{\max }$ for the indoor VLC channel can be calculated following [51], which is given by:

$$
R_{\max } \leq \frac{1}{10 D_{\mathrm{rms}_{\operatorname{Max}}}}
$$

In order to evaluate the positioning accuracy, we have to consider the Cramer-Rao bound (CRB) [52] as a performance reference, which is the lower bound on the mean square estimation error in the set of unbiased estimates. Typical CRB ranges within the rooms for 4-, 6- and 9-cell configurations were derived for an optimized Lambertian order (OLO) LED case for an indoor cellular optical wireless communication system in [53]. Simulations of particular scenario revealed reached values of CRB from $12.8 \mathrm{~cm}$, from $8.6 \mathrm{~cm}$ and from $5.8 \mathrm{~cm}$, respectively, for above mentioned cells' deployment in for rooms of $5 \times 5 \times 3 \mathrm{~m}^{3}$, $4 \times 6 \times 3 \mathrm{~m}^{3}$, and $5 \times 5 \times 3 \mathrm{~m}^{3}$ [53]. This has shown VLC as very useful tool for developers of indoor positioning systems.

\subsection{Car-to-Car Communications}

VLC can also be utilized for outdoor applications such as the public transport. Note how the infrastructure of public lights has changed over the last 5 years. Typical incandescent lamps have been replaced by LED lighting across whole cities. For example the Los Angeles LED Streetlight Replacement Program has replaced over 140,000 existing streetlights in the city with LED units which has brought energy saving $68 \mathrm{GWh} /$ year and money saving \$ 10M/year [54].

Several test use-cases and experimental results have been published for a vehicular VLC network consisting of on-board units, vehicles, and road side units, i.e., traffic lights, street lamps, digital signage etc. Cars fitted with LED-based front and back lights can communicate with each other and with the road side units (RSUs) through the VLC technology. Furthermore, LED-based RSUs can be used for both signaling and broadcasting safety-related 


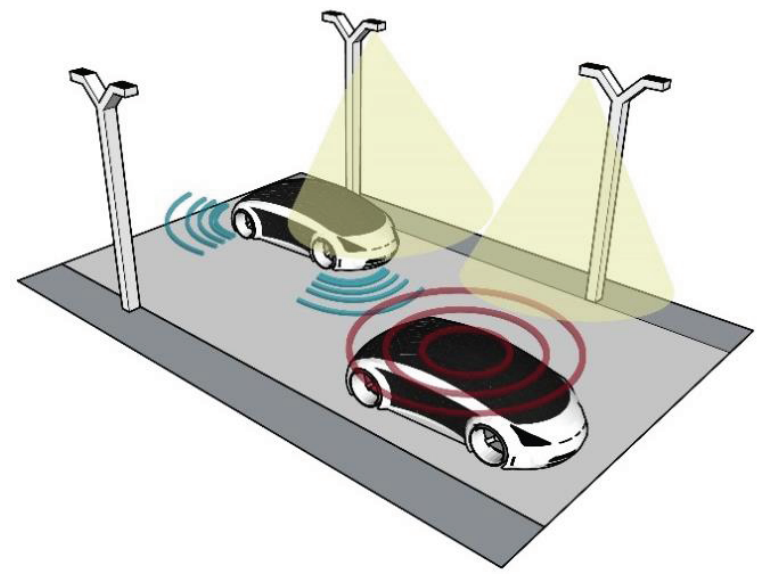

Fig. 8. Concept of VLC for car to car and car to infrastructure.

information to vehicles on the road. Such a network is illustrated in Fig. 8.

An analytical performance analysis of VLC based carto-car communications for a range of communication geometries consider both the LOS and NLOS paths over a link span of $20 \mathrm{~m}$ at a data rate of $2 \mathrm{Mbps}$ was outlined in [55]. Optical wireless communications systems based on an LED transmitter and camera receiver was proposed for automotive applications in [56]. The signal reception experiment has been performed for static and moving camera receivers. Up to $15 \mathrm{Mb} / \mathrm{s}$ error-free throughput under fixed conditions was sustained. This represents very good performance for optical wireless communication systems, since the experiment did not involve further correction methods like coding and equalization. In [57] it was shown that the receiver in the driving situation can detect and accurately track an LED transmitter array with error-free communication over distances of 25-80 m. Further tests and experiments are however needed to prove these concepts.

\section{Conclusion}

The research and development in VLC at a global level has increased more than ten times for last two years. This paper gave an overview of VLC and its use in a number of applications. In outdoor environment VLC can provide internet hot spots using street lighting and mobile access as part of the 5G technology in highly congested areas and within indoor environment it can be used for localization and small cells coverage networks. VLC has been accepted as part of the 802.15.7 task group and is being proposed as a supplement technology in $5 \mathrm{G}$ networks. We assume further increase of research efforts within selected applications.

\section{Acknowledgements}

This joint research is supported by the EU COST ICT Action IC1101 Optical Wireless Communications:
An Emerging Technology (OPTICWISE) and by the Grant Agency of the Czech Technical University in Prague, grant no. SGS14/190/OHK3/3T/13.

\section{References}

[1] C. V. N. Index, Global Mobile Data Traffic Forecast Update, 2014-2019, White paper, ed. 2013

[2] BANGERTER, B., TALWAR, S., AREFI, R., STEWART, K. Networks and devices for the $5 \mathrm{G}$ era. IEEE Communications Magazine, 2014, vol. 52, p. 90-96. DOI: 10.1109/MCOM.2014.6736748

[3] WANG CHENG-XIANG, HAIDER, F., XIQI GAO, XIAO-HU YOU, YANG YANG, DONGFENG YUAN, et al. Cellular architecture and key technologies for $5 \mathrm{G}$ wireless communication networks. IEEE Communications Magazine, 2014, vol. 52, p. 122 to 130. DOI: $10.1109 / \mathrm{MCOM}$.2014.6736752

[4] LI, Q. C., HUANING NIU, PAPATHANASSIOU, A., GENG WU. 5G network capacity: Key elements and technologies. IEEE Vehicular Technology Magazine, 2014, vol. 9, no. 1, p. 71-78. DOI: 10.1109/MVT.2013.2295070

[5] YONG SHENG SOH, QUEK, T. Q. S., KOUNTOURIS, M., HYUNDONG SHIN. Energy efficient heterogeneous cellular networks. IEEE Journal on Selected Areas in Communications, 2013, vol. 31, p. 840-850. DOI: 10.1109/JSAC.2013.130503

[6] HU, R. Q., YI QUIAN. An energy efficient and spectrum efficient wireless heterogeneous network framework for $5 \mathrm{G}$ systems. IEEE Communications Magazine, 2014, vol. 52, p. 94-101. DOI: 10.1109/MCOM.2014.6815898

[7] PARCA, G., SHAHPARI, A., CARROZZO, V., TOSI BELEFFI, G. M., TEIXEIRA, A. L. J. Optical wireless transmission at 1.6-Tbit/s $(16 \times 100 \mathrm{Gbit} / \mathrm{s})$ for next-generation convergent urban infrastructures. Optical Engineering, 2013, vol. 52, no. 11, p. 116102. DOI: 10.1117/1.OE.52.11.116102

[8] COSSU, G., KHALID, A. M., CHOUDHURY, P., CORSINI, R., CIARAMELLA, E. 3.4 Gbit/s visible optical wireless transmission based on RGB LED. Optics Express, 2012, vol. 20, no. 26, p. B501-B506. DOI: 10.1364/OE.20.00B501

[9] BURrougheS, J. H., BRADLEY, D. D. C., BROWN, A. R., MARKS, R. N., MACKAY, K., FRIEND, R. H., et al. Lightemitting diodes based on conjugated polymers. Nature, 1990, vol. 347 , p. $539-541$. DOI:10.1038/347539a0

[10] TANG, C. W., VANSLYKE, S. A. Organic electroluminescent diodes. Applied Physics Letters, 1987, vol. 51, p. 913-915. DOI: $10.1063 / 1.98799$

[11] MCKENDRY, J. J. D., GREEN, R. P., KELLY, A. E., ZHENG, G., GUILHABERT, B., MASSOUBRE, D., et al. High-speed visible light communications using individual pixels in a micro light-emitting diode array. IEEE Photonics Technology Lett., 2010 vol. 22 , no. 18 , p. 1346-1348. DOI: 10.1109/LPT.2010.2056360

[12] HAIGH, P. A., GHASSEMLOOY, Z., RAJBHANDARI, S., PAPAKONSTANTINOU, I., POPOOLA, W. Visible light communications: $170 \mathrm{Mb} / \mathrm{s}$ using an artificial neural network equalizer in a low bandwidth white light configuration. Journal of Lightwave Technology, 2014, vol. 32, no. 9, p. 1807-1813. DOI: 10.1109/JLT.2014.2314635

[13] MCKENDRY, J. J. D., MASSOUBRE, D., ZHANG, S., RAE, B. R., GREEN, R. P., GU, E., et al. Visible-light communications using a CMOS-controlled micro-light-emitting-diode array. Journal of Lightwave Technology, 2012, vol. 30, no. 1, p. 61-67. DOI: 10.1109/JLT.2011.2175090

[14] TSONEV, D., HYUNCHAE, C., RAJBHANDARI, S., MCKENDRY, J. J. D., VIDEV, S., GU, E., et al. A 3-Gb/s single-LED 
OFDM-based wireless VLC link using a gallium nitride $\mu$ LED IEEE Photonics Technology Letters, 2014, vol. 26, p. 637-640. DOI: 10.1109/LPT.2013.2297621

[15] KHALID, A. M., COSSU, G., CORSINI, R., CHOUDHURY, P., CIARAMELLA, E. 1-Gb/s transmission over a phosphorescent white LED by using rate-adaptive discrete multitone modulation. IEEE Photonics Journal, 2012, vol. 4, p. 1465-1473. DOI: 10.1109/JPHOT.2012.2210397

[16] SINGH, R. Global Organic Electronics Market (Application and Geography) - Size, Share, Global Trends, Company Profiles, Demand, Insights, Analysis, Research, Report, Opportunities, Segmentation and Forecast, 2013 - 2020. 2014.

[17] HAIGH, P. A., BAUSI, F., LE MINH, H., PAPAKONSTANTINOU, I., POPOOLA, W., BURTON, A., et al. Wavelength-multiplexed polymer LEDs: Towards $55 \mathrm{Mb} / \mathrm{s}$ organic visible light communications. IEEE Journal on Selected Areas in Communications. Accepted, 2014.

[18] HAIGH, P. A., GHASSEMLOOY, Z., RAJBHANDARI, S., PAPAKONSTANTINOU, I. Visible light communications using organic light emitting diodes. IEEE Communications Magazine, 2013, vol. 51, p. 148-154. DOI: 10.1109/MCOM.2013.6576353

[19] BARLOW, I. A., KREOUZIS, T., LIDZEY, D. G. High-speed electroluminescence modulation of a conjugated-polymer light emitting diode. Applied Physics Letters, 2009, vol. 94, p. $243301-$ 3. DOI: $10.1063 / 1.3147208$

[20] HAIGH, P. A., GHASSEMLOOY, Z., PAPAKONSTANTINOU, I. 1.4-Mb/s white organic LED transmission system using discrete multitone modulation. IEEE Photonics Technology Letters, 2013, vol. 25, no. 6, p. 615-618. DOI: 10.1109/LPT.2013.2244879

[21] HAIGH, P. A., GHASSEMLOOY, Z., PAPAKONSTANTINOU, I. HOA LE MINH. $2.7 \mathrm{Mb} / \mathrm{s}$ with a $93-\mathrm{kHz}$ white organic light emitting diode and real time ANN equalizer. IEEE Photonics Technology Letters, 2013, vol. 25, no. 17, p. 1687-1690. DOI: 10.1109/LPT.2013.2273850

[22] HAigh, P. A., BAUSI, F., KANESAN, T., LE, S. T., RAJBHANDARI, S., GHASSEMLOOY, Z., et al. A $20-\mathrm{Mb} / \mathrm{s}$ VLC link with a polymer LED and a multilayer perceptron equalizer. IEEE Photonics Technology Letters, 2014, vol. 26, p. 1975-1978. DOI: 10.1109/LPT.2014.2343692

[23] LE, S. T., KANESAN, T., BAUSI, F., HAIGH, P. A., RAJBHANDARI, S., GHASSEMLOOY, Z., et al. $10 \mathrm{Mb} / \mathrm{s}$ visible light transmission system using a polymer light-emitting diode with orthogonal frequency division multiplexing. Optics Letters, 2014, vol. 39, p. 3876-3879. DOI: 10.1364/OL.39.003876

[24] BRABEC, C. J., SARICIFTCI, N. S., HUMMELEN, J. C. Plastic solar cells. Advanced Functional Materials, 2001, vol. 11, no. 1, p. 15-26.

[25] TEDdE, S. F., KERN, J., STERZL, T., FURST, J., LUGLi, P., HAYDEN, O. Fully spray coated organic photodiodes. Nano Letters, 2009, vol. 9, p. 980-3. DOI: 10.1021/n1803386y

[26] HAIGH, P. A., GHASSEMLOOY, Z., HOA LE MINH, RAJBHANDARI, S., ARCA, F., TEDDE, S. F., et al. Exploiting equalization techniques for improving data rates in organic optoelectronic devices for visible light communications. Journal of Lightwave Technology, 2012, vol. 30, no. 19, p. 3081-3088. DOI: 10.1109/JLT.2012.2210028

[27] GHASSEMloOy, Z., HAigh, P. A., ARCA, F., TEDDE, S. F., HAYDEN, O., PAPAKONSTANTINOU, I., et al. Visible light communications: $3.75 \mathrm{Mbits} / \mathrm{s}$ data rate with a $160 \mathrm{kHz}$ bandwidth organic photodetector and artificial neural network equalization. [Invited] Photonics Research, 2013, vol. 1, no. 2, p. 65-68. DOI: 10.1364/PRJ.1.000065

[28] HAIGH, P. A., GHASSEMLOOY, Z., PAPAKONSTANTINOU, I., ARCA, F., TEDDE, S. F., HAYDEN, O., et al. A $1-\mathrm{Mb} / \mathrm{s}$ visible light communications link with low bandwidth organic components. IEEE Photonics Technology Letters, 2014, vol. 26, no. 13, p. 1295-1298. DOI: 10.1109/LPT.2014.2321412

[29] AZHAR, A. H., TRAN, T., O'BRIEN, D. A Gigabit/s indoor wireless transmission using MIMO-OFDM visible-light communications. IEEE Photonics Technology Letters, 2013, vol. 25, no. 2, p. 171-174. DOI: 10.1109/LPT.2012.2231857

[30] TEICHMANN, V. S. C., BARRETO, A. N., PHAM, T. T., RODES, R., MONROY, I. T., MELLO, D. A. A. SC-FDE for MMF short reach optical interconnects using directly modulated $850 \mathrm{~nm}$ VCSELs. Optics Express, Nov 5 2012, vol. 20, no. 23, p. 25369-25377. DOI: 10.1364/OE.20.025369

[31] ELGALA, H., LITTLE, T. D. C. Polar-based OFDM and SC-FDE links toward energy-efficient Gbps transmission under IM-DD optical system constraints [Invited]. Journal of Optical Communications and Networking, 2015/02/01, vol. 7, no. 2, p. A277-A284. DOI: 10.1364/JOCN.7.00A277

[32] WU, F. M., LIN, C. T., WEI, C. C., CHEN, C. W., CHEN, Z. Y., HUANG, H. T., et al. Performance comparison of OFDM signal and CAP signal over high capacity RGB-LED-based WDM visible light communication. IEEE Photonics Journal, 2013, vol. 5, article no. 7901507. DOI: 10.1109/JPHOT.2013.2271637

[33] OLMEDO, M. I., TIANJIAN ZUO, JENSEN, J. B., QIWEN ZHONG, XIAOGENG XU, POPOV, S., et al. Multiband carrierless amplitude phase modulation for high capacity optical data links. Journal of Lightwave Technology, 2014, vol. 32, no. 4, p. 798-804. DOI: 10.1109/JLT.2013.2284926

[34] HAIGH, P. A., LE, S. T., ZVANOVEC, S., GHASSEMLOOY, Z., LUO, P., XU, T., et al. Multi-band carrier-less amplitude and phase modulation for bandlimited visible light communications systems. IEEE Wireless Communication Magazine. In print, 2015.

[35] HAIGH, P. A., BURTON, A., WERFLI, K., HOA LE MINH, BENTLEY, E., CHVOJKA, P., et al. A multi-CAP visible light communications system with $4.85 \mathrm{~b} / \mathrm{s} / \mathrm{Hz}$ spectral efficiency. IEEE Journal on Selected Areas in Communications. Accepted, 2015.

[36] IEEE 802.15 WPAN Ta Task Group 7 (TG7) Visible Light Communication. [Online] Cited 2015-03-05. Available at: http://www.ieee802.org/15/pub/TG7.html

[37] LEE, K., PARK, H., BARRY, J. R. Indoor channel characteristics for visible light communications. IEEE Communications Letters, 2011, vol. 15, no. 2, p. 217-219. DOI: 10.1109/LCOMM.2011.010411.101945

[38] BARRY, J. R., KAHN, J. M., KRAUSE, W. J., LEE, E. A., MESSERSCHMITT, D. G. Simulation of multipath impulse response for indoor wireless optical channels. IEEE Journal on Selected Areas in Communications, 1993, vol. 11, p. 367-379. DOI: $10.1109 / 49.219552$

[39] LANGER, K.-D., HILT, J., SHULZ, D., LASSAK, F., HARTLIEB, F., KOTTKE, C., et al. Rate-adaptive visible light communication at $500 \mathrm{Mb} / \mathrm{s}$ arrives at plug and play. Optoelectronics \& Communications, SPIE Newsroom, 2013. DOI: $10.1117 / 2.1201311 .005196$

[40] GROBE, L., PARASKEVOPOULOS, A., HILT, J., SCHULZ, D., LASSAK, F., HARTLIEB, F., et al. High-speed visible light communication systems. IEEE Communications Magazine, 2013, vol. 51, no. 12, p. 60-66. DOI: 10.1109/MCOM.2013.6685758

[41] JUNGNICKEL, V., POHL, V., NONNIG, S., VON HELMOLT, C. A physical model of the wireless infrared communication channel. IEEE Journal on Selected Areas in Communications, 2002, vol. 20, p. 631-640. DOI: 10.1109/49.995522

[42] JIVKOVA, S., KAVEHRAD, M. Shadowing and blockage in indoor optical wireless communications. In IEEE Global Telecommunications Conference GLOBECOM '03. 2003, vol. 6, p. 3269-3273. DOI: 10.1109/GLOCOM.2003.1258840

[43] KOMINE, T., NAKAGAWA, M. A study of shadowing on indoor visible-light wireless communication utilizing plural white LED 
lightings. In $1^{\text {st }}$ International Symposium on Wireless Communication Systems. 2004, p. 36-40. DOI: 10.1109/ISWCS.2004.1407204

[44] CHVOJKA, P., ZVANOVEC, S., HAIGH, P. A., GHASSEMLOOY, Z. Channel characteristics of visible light communications within dynamic indoor environment. Journal of Lightwave Technology, 2015, vol. 33, no. 9, p. 1719-1725. DOI: 10.1109/JLT.2015.2398894

[45] LIU, H. S., PANG, G. Positioning beacon system using digital camera and LEDs. IEEE Transactions on Vehicular Technology, 2003, vol. 52, no. 2, p. 406-419. DOI: 10.1109/TVT.2002.808800

[46] KATAYAMA, MUTSUMI, M. KAZUYUKI, K. KAZUMITSU, Vehicle position detection system. JP Patent, 2010.

[47] ARAFA, A., XIAN JIN, KLUKAS, R. Wireless indoor optical positioning with a differential photosensor. IEEE Photonics Technology Letters, 2012, vol. 24, no. 12, p. 1027-1029. DOI: 10.1109/LPT.2012.2194140

[48] PENGFEI LUO, GHASSEMLOOY, Z., HOA LE MINH, KHALIGHI, A., XIANG ZHANG, MIN ZHANG, et al. Experimental demonstration of an indoor visible light communication positioning system using dual-tone multi-frequency technique. In $20143 \mathrm{rd}$ International Workshop in Optical Wireless Communications (IWOW). 2014, p. 55-59. DOI: 10.1109/IWOW.2014.6950776

[49] WANG, T. Q., SEKERCIOGLU, Y. A., NEILD, A., ARMSTRONG, J. Position accuracy of time-of-arrival based ranging using visible light with application in indoor localization systems. Journal of Lightwave Technology, 2013, vol. 31, no. 20, p. 3302-3308. DOI: 10.1109/JLT.2013.2281592

[50] CARRUTHERS, J. B., CAROLL, S. M., KANNAN, P. Propagation modelling for indoor optical wireless communications using fast multi-receiver channel estimation. IEE ProceedingsOptoelectronics, 2003, vol. 150, no. 5, p. 473-481. DOI: 10.1049/ip-opt:20030527

[51] RAPPAPORT, T. S. Wireless Communications. Prentice-Hall, 2002.

[52] MCDONOUGH, R. N., WHALEN, A. D. Detection of Signals in Noise. San Diego (CA, USA): Wiley, 1995.

[53] WU, D., GHASSEMLOOY, Z., ZHONG, W.-D., KHALIGHI, M.A., HOA LE MINH, CHEN, C., et al. Effect of optimal Lambertian order on the performance of cellular indoor optical wireless communications and positioning. Journal of Lightwave Technologies, 2015, submitted.

[54] The LED Streetlight Replacement Program. [Online] Cited 2014 02-10 Available at: http://bsl.lacity.org/led.html

[55] PENGFEI LUO, GHASSEMLOOY, Z., HOA LE MINH, BENTLEY, E., BURTON, A., TANG, X. Performance analysis of a car-to-car visible light communication system. Applied Optics, 2015, vol. 54, no. 7, p. 1696-1706. DOI: 10.1364/AO.54.001696

[56] TAKAI, I., ITO, S., YASUTOMI, K., KAGAWA, K., ANDOH, M., KAWAHITO, S. LED and CMOS image sensor based optical wireless communication system for automotive applications. IEEE Photonics Journal, 2013, vol. 5, article no. 6801418. DOI: 10.1109/JPHOT.2013.2277881

[57] NAGURA, T., YAMAZATO, T., KATAYAMA, M., YENDO, T., FUJII, T., OKADA, H. Tracking an LED array transmitter for visible light communications in the driving situation. In 20107 th International Symposium on Wireless Communication Systems (ISWCS). 2010, p. 765-769. DOI: 10.1109/ISWCS.2010.5624361

\section{About the Authors ...}

Stanislav ZVANOVEC received his M.Sc. and Ph.D. from the Czech Technical University in Prague, in 2002 and 2006, respectively. Now he is a full professor and vicehead of the Department of Electromagnetic Field at the Faculty of Electrical Engineering, Czech Technical University in Prague. He leads a Free-space and Fiber Optics team from the Faculty of Electrical Engineering, CTU and several research projects. His current research interests include wireless optical communications, visible light communications, remote sensing and optical fiber sensors.

Petr CHVOJKA was born in 1987. He received his M.Sc. from the Czech Technical University in Prague in 2013. Now he is a postgraduate student and a researcher at the Department of Electromagnetic Fields, Czech Technical University in Prague, where he is a member of a Free-space and Fiber Optics team. His research area includes visible light communications, OLED technologies and wireless optical communications.

Paul Anthony HAIGH received the $\mathrm{PhD}$ degree in Visible Light Communications from Northumbria University in 2014, publishing 13 articles in high ranking journals. Between 2010 and 2011 he held the prestigious Marie Curie Fellowship at CERN where he worked on optoelectronic links for large hadron collider experiments. In 2010 Paul received the BEng (Hons) degree in Communications Engineering from Northumbria University. Currently, he is a Research Associate within the High Performance Networks group at the University of Bristol working on the EPSRC TOUCAN project. His research is focused on real time seamless, transparent and adaptive and programmable interfaces between wireless and wired multi-technology networks.

Zabih GHASSEMLOOY, CEng, Fellow of IET, Senior Member of IEEE received his BSc (Hons) from the Manchester Metropolitan University in 1981, and MSc and PhD from the University of Manchester, Institute of Science and Technology (UMIST), in 1984 and 1987, respectively. 1986-87 worked in UMIST and from 1987 to 1988 was a Post-doctoral Research Fellow at the City University, London. 1988 joined Sheffield Hallam University as a Lecturer, becoming a Professor in Optical Communications in 1997. 2004-2012 was an Associate Dean for Research in the School of Computing, Engineering and from 2012-2014 Associate Dean for Research and Innovation in the Faculty of Engineering and Environment, Northumbria University at Newcastle, UK. He currently heads the Northumbria Communications Research Laboratories within the Faculty. $\mathrm{He}$ is the Editor-in-Chief of the International Journal of Optics and Applications, and British Journal of Applied Science \& Technology. His researches interests are on optical wireless communications, visible light communications and radio over fiber/free space optics. He has supervised over $48 \mathrm{PhD}$ students and published more than 550 papers (195 in journals +4 books). He is a co-author of a CRC book on "Optical Wireless Communications - Systems and Channel Modelling with Matlab (2012)". From 2004-06 he was the IEEE UK/IR Communications Chapter Secretary, the Vice-Chairman (2004-2008), the Chairman (2008-2011), and Chairman of the IET Northumbria Network (Oct 2011-). 